\title{
Sex in the Time of COVID-19: Patterns of Sexual Behavior Among LGBTQ+ Individuals in the U.S.
}

\author{
Marybec Griffin ${ }^{1,2}$ (D) Jessica Jaiswal2,3,4 $\cdot$ Richard J. Martino ${ }^{2} \cdot$ Caleb LoSchiavo ${ }^{1,2} \cdot$ Camilla Comer-Carruthers $^{1,2}$. \\ Kristen D. Krause ${ }^{1,2} \cdot$ Christopher B. Stults ${ }^{2,5} \cdot$ Perry N. Halkitis ${ }^{1,2,6}$
}

Received: 9 April 2021 / Revised: 21 December 2021 / Accepted: 20 January 2022 / Published online: 9 February 2022

(c) The Author(s), under exclusive licence to Springer Science+Business Media, LLC, part of Springer Nature 2022

\begin{abstract}
The SARS-CoV-2 virus, the pathogen which causes COVID-19, has left an indelible impact on the daily lives of individuals in the USA. This study sought to explore the sexual behaviors among people in the LGBTQ+ population at the onset of the pandemic. Behaviors were explored across sub-groups of the population. The study employed data from an internet survey about the impact of COVID-19 on LGBTQ+identified individuals conducted between May and July 2020. The final sample was comprised of 1090 participants from across the USA. Overall, sexual activity and the number of sexual partners decreased after March 13, 2020 (as compared to before this date) across all sexual orientation groups; however, living situation and partnership status supported sexual activity. Gay and bisexual men living with a partner or a spouse ( $\mathrm{AOR}=2.20, p=.023$ ) and those living with a non-romantic roommate or friend ( $\mathrm{AOR}=2.88$, $p=.004)$ reported more sexual activity. For both cisgender lesbian and bisexual women and transgender and non-binary individuals, those who were married or in a domestic partnership ( $\mathrm{AOR}=4.54, p<.001$; $\mathrm{AOR}=9.97, p<.001$, respectively) and those in a committed relationship $(\mathrm{AOR}=3.54, p=.001 ; \mathrm{AOR}=8.46, p<.001$, respectively) reported more sexual activity. Additionally, cisgender lesbian and bisexual women living with their partner or spouse ( $\mathrm{AOR}=2.14, p=.044)$ reported more sexual activity. When examining the number of sexual partners, cisgender lesbian and bisexual women and transgender and non-binary individuals in a committed relationship ( $\mathrm{AOR}=0.31, p<0.001 ; \mathrm{AOR}=0.26, p=.004$, respectively) and those living with a partner or spouse ( $\mathrm{AOR}=0.30$, $p=.002 ; \mathrm{AOR}=0.25, p=.028$, respectively) were less likely to report two or more sexual partners. Examining the changes in sexual activity and number of sexual partners helps us better identify the effects of COVID-19 on intimate relationships and sexual behaviors. Furthermore, this study may help develop clinical best practices to facilitate risk-reduction strategies for LGBTQ+ populations when engaging in sexual activity within a communicable disease framework. Current guidance on sexual activity within a pandemic has created a unique opportunity for sex-positive public health messaging that protects individual health while also offering a framework for conversations about risk mitigation that is applicable for both COVID-19 and STI/HIV prevention.
\end{abstract}

Keywords Sexual behavior · Concurrent partners · Sexual orientation · Changes in sexual behavior · LGBTQ $\cdot$ COVID-19

Marybec Griffin

mcg197@sph.rutgers.edu

1 Department of Health Behavior, Society and Policy, Rutgers School of Public Health, Rutgers University, 683 Hoes Lane West, Piscataway, NJ 08854, USA

2 Center for Health, Identity, Behavior and Prevention Studies, Rutgers University, Piscataway, NJ, USA

3 Department of Health Science, University of Alabama, Tuscaloosa, AL, USA
4 Center for Interdisciplinary Research on AIDS, Yale University, New Haven, CT, USA

5 Psychology Department, Baruch College, City University of New York, New York, NY, USA

6 Department of Biostatistics and Social and Behavioral Health Sciences, Rutgers School of Public Health, Rutgers University, Piscataway, NJ, USA 


\section{Introduction}

For many members of the lesbian, gay, bisexual, transgender, and queer (LGBTQ+) population, this is not the first time a viral pandemic has significantly impacted their daily lives thereby affecting daily activities including information sharing, care work, and changes in sexual behavior that include prevention strategies. Similar to the human immunodeficiency virus (HIV) pandemic, with the SARS-CoV-2 (COVID-19) virus, sexual activity poses a risk for transmission of a viral agent due to close contact (Centers for Disease Control and Prevention, 2020; Turban et al., 2020) and may lead to stigmatization of decisions to engage in sexual behaviors during a time of mandated or recommended quarantines (Banerjee \& Nair, 2020; Newman \& Guta, 2020; Turban et al., 2020). Many international and US-based health organizations have cautioned for sexually active individuals to take precautions when engaging in sexual activity and reduce their number of partners during the pandemic (Centers for Disease Control and Prevention, 2020; Pérez-Figueroa et al., 2021; Turban et al., 2020). One specific challenge of the COVID-19 pandemic is that in order to disrupt the viral transmission pathway, social interactions must be reduced or severely limited (Centers for Disease Control \& Prevention, 2020; Newman \& Guta, 2020). This may be especially challenging to people who are not in cohabitating relationships or those in non-monogamous relationships (Alpalhão \& Filipe, 2020; Centers for Disease Control \& Prevention, 2020; Lindberg et al., 2020; Newman \& Guta, 2020).

The pursuit of sexual satisfaction is an innate part of the human experience (Alpalhão \& Filipe, 2020; Centers for Disease Control \& Prevention, 2020; Lenke \& Piehl, 2009; Newman \& Guta, 2020; Turban et al., 2020; World Health Organization, 2010), and further adding to this challenge is the sense of interpersonal connection that is created when engaging in sexual activity (Newman \& Guta, 2020; Turban et al., 2020). Recent studies have demonstrated the reduction in sexual activity during the COVID-19 pandemic overall (Lehmiller et al., 2021; Li et al., 2020) including reductions in the number of people watching pornography (Grubbs et al., 2021; Zattoni et al., 2020); however, the specific impact of the COVID-19 pandemic on LGBTQ+ populations warrants specific research. Moreover, stay-at-home orders further disrupt the social nature of human relationships (Alpalhão \& Filipe, 2020; Turban et al., 2020), negatively impact mental health (Fish et al., 2020; Kneale \& Becares, 2020; Krause, 2021) and impact sexual activity in two distinct ways: reducing the desire to engage in sexual activity with partners inside the home and reducing the opportunity to engage in sexual activity with partners outside the home. Given these divergent reasons for limiting sexual activity and partners, a more nuanced examination of the sexual experiences of LGBTQ+individuals in the USA will allow for a more complete understanding of the impacts of the COVID-19 pandemic on this population.
An emerging set of studies have begun to establish that the COVID-19 pandemic has affected the sexual behaviors of LGBTQ+ people. Data from a national survey of gay and bisexual men found that in period between April 10 and May 10, 2020, nearly 50\% of the men reported not having sex (McKay et al., 2020). Among gay and bisexual men who were sexually active between April 10 and May 10, 78\% of them reported having only one partner and for $9 \%$ reported having more than one partner (McKay et al., 2020). In contrast, a national study found that $48 \%$ of gay and bisexual men reported no change in the number of sexual partners and the mean number of sexual partners increased by 2.3 sexual partners (Sanchez et al., 2020). Men between the ages of 25-44 were more likely to report an increase in the number of anal sex partners as compared to men between the ages of 18-24 (Sanchez et al., 2020). While there is not specific data for lesbian women, a study of the sexual effects of COVID-19 among Polish cisgender women found a significant increase in the number of women abstaining from sex after the start of the pandemic (Fuchs et al., 2020). A study of transgender and non-binary individuals in Brazil found that nearly half of all participants were abstaining from sex and $78.6 \%$ reported a decrease in the number of sexual partners (Torres et al., 2021). However, population-based estimates cannot be ascertained as national epidemiological and census data fail to capture SOGI date (Phillips II et al., 2020), necessitating reliance on smaller scale studies to capture these phenomena.

The burgeoning scholarship on the effects of the COVID-19 pandemic only begin to explain the myriad effects on social relationships. This study contributes to the literature by examining the effects of the COVID-19 pandemic on the sexual relationships, most notably the sexual behaviors and number of sexual partners, among gay or bisexual cisgender men, lesbian or bisexual cisgender women, and transgender and non-binary individuals of any sexual orientation. Sexual intimacy is an important aspect of our humanity and for the LGBTQ+ community may represent a physical manifestation of their identities (Alpalhão \& Filipe, 2020; Lenke \& Piehl, 2009; Newman \& Guta, 2020; Scroggs et al., 2020; Turban et al., 2020; World Health Organization, 2010), especially given the historical repression and criminalization of the expression of physical and emotional intimacy among same sex couples (Human Rights Campaign, 2021). Previous studies have demonstrated that engagement in casual sexual activity is higher among members of the LGBTQ+ community (Alpalhão \& Filipe, 2020), particularly gay men (Newman \& Guta, 2020). To better understand factors associated with engaging in sexual activity and the number of sexual partners, we compared self-reported sexual behaviors among a nationally representative sample of participants in an internet-based survey of LGBTQ+individuals, stratified by gender identity and sexual orientation. 


\section{Method}

\section{Participants and Procedure}

This study was cross-sectional and internet-based recruitment strategy between May and July 2020. The purpose of this study was to understand the immediate impact of COVID-19 on LGBTQ+individuals living in the USA. In order to participate in the study, participants were assessed via the following inclusion criteria: (1) be 18 years old older, (2) self-identify as LGBTQ+, and (3) live in the USA or the US territories. The survey included measures assessing sociodemographics, sexual behavior, substance use, mental health, general health, intimate partner violence, healthcare access, medication access and adherence, and access to COVID-19 healthcare services. The Rutgers University Institutional Review Board approved the study protocol (2021000063).

Research staff recruited participants in stages via LGBTQ+ listservs, professional organization listservs, institutional social media accounts, and personal social media accounts. Data were collected using Qualtrics and included the selecting all data quality and bot-detection safeguards offered by the software. Despite these mechanisms, bots were able to evade the Qualtrics-designed bot protection questions. To address this issue, research staff developed a bot identification and data cleaning protocol which has been described in detail in a previous study (Griffin et al., 2021). Briefly, the survey was first launched in the first week of May 2020. Research staff noticed an unusually high number of responses in the first two days of data collection. Data collection was paused to allow for data integrity screening which led to the detection of bots submitting multiple responses. Responses were flagged for the any of the following reasons: participant completed less than $60 \%$ of the survey, low reCAPTCHA score, response time that was less than five minutes or more than $30 \mathrm{~min}$, contained exact duplicate responses to the qualitative question, removing surveys with conflicting data on demographic questions (e.g., reporting living in a rural area but providing a ZIP code for a large metropolitan area). All flagged responses were removed from the analytic sample. Data collection resumed after additional safeguards were added. The two surveys contained identical response items; however, the second launch included duplicate demographic questions to help identify discrepancies between answers provided in the screener questions and the survey questions. Additionally, the incentive structure changed from all respondents receiving a $\$ 5$ gift card to a raffle-based incentive system. In the second phase, they would be entered into a raffle for a chance to win one of ten $\$ 100$ gift cards if they provided their email address.

Across both waves of data collection, potential participants answered several screener questions to determine eligibility at the beginning of the Qualtrics survey. If eligible, the participant then provided tacit consent prior to enrollment. Upon completion of the COVID-19 survey, participants were asked if they would like to complete a second optional incentive survey to be entered into the compensation raffle. Participants entered their email address in this survey. No other identifying information was collected. Participants also had the option to complete the COVID-19 survey without completing the incentive survey.

The sample for this study comprised of 1090 participants who met the inclusion criteria. All participants in the study provided answers to the following variables of interest: age, race and ethnicity, relationship status, living arraignment, type of sexual behavior and number of sexual partners.

\section{Measures}

\section{Gender Identity}

All participants were asked to report their both their current gender identity and their assigned sex at birth. For gender identity, participants could select from the following categories: male, female, transgender male, transgender female, non-binary/genderqueer/gender non-conforming, or different identity with the option to specify. These response choices were selected as they align with current Department of Health and Human Services and Health Resources and Services Administration guidelines on collecting gender identity (Orientation \& Surveys, 2016). Sex assigned at birth was recorded via two different answer choices, male or female. Participants who reported their gender as male and their sex at assigned birth as male were then recoded as cisgender males. The same process was used to recode for cisgender women. Participants who reported their gender as female and indicated their sex at birth was female. Those participants that selected male as their gender and female for sex assigned at birth were recoded as transgender men and those who selected female as their gender and male for sex assigned at birth were recorded as transgender women. Those that reported their gender as transgender women or transgender men remained in those categories. For participants that selected non-binary/genderqueer/gender non-conforming remained in this category. For the purposes of this analysis, all transgender and non-binary/genderqueer/gender nonconforming were recoded into one group.

\section{Sexual Orientation}

Participants were asked to provide their sexual orientation as it corresponded to the following groups: heterosexual or straight, gay or lesbian, bisexual, or different identity with the option to specify. Heterosexual participants were removed from the sample unless they reported a transgender or nonbinary/genderqueer/gender non-conforming gender identity. These participants were included in the transgender group 
regardless of sexual identity. Bisexual individuals were divided into two different groups: bisexual cisgender men and bisexual cisgender women. Participants indicating they were gay or lesbians were also recoded along with their gender identity if they were cisgender.

\section{Age}

Participants were asked to report their age. The responses were then recoded in the following groups: $18-29,30-39$, $40-49$, and 50 and older.

\section{Race and Ethnicity}

Participants were asked to report their racial and ethnic background as it corresponded to the following groups: Asian, Black/African American, Hispanic or Latinx, Middle Eastern/North African, Native American or Alaska Native, Native Hawaiian or Pacific Islander, White or different identity with the option to specify. These racial and ethnic groups conform to the current US Office of Management and Budget Standards for Maintaining, Collecting, and Presenting Federal Data on Race and Ethnicity (Wallman et al., 2000). For statistical purposes, the responses were then collapsed into the following groups: white Non-Hispanic and participants of color.

\section{Relationship Status}

Participants were asked about their relationship status and could choose from the following options: single, in a committed relationship (without legal status), in a domestic partnership/civil union/other legal status besides marriage, married, separated from partner/divorced, widowed. For the purposes of this analysis, the following groups were created: married/domestic partnership, in a committed relationship, and single/separated/divorced/widowed.

\section{Living Arrangement}

Initial data were collected on the number of people in each respondent's household. Participants reporting zero lived alone. Anyone living with more than one person was asked about their relationship to the other people in the household via the following prompt: What is the relationship of the person (people) living with you? Participants could select all that applied: partner/spouse, roommate (non-romantic or nonsexual partner), friends, or family. For the purposes of this analysis, any participant who reported that they lived with a partner/spouse and any other category was collapsed into the group partner/spouse. Anyone reporting that they lived alone was coded as such. All other categories were assigned based on their responses. We also collapsed roommate (nonromantic or non-sexual partner) and friends.

\section{Sexual Behaviors}

Participants were asked about the types of sexual activity (oral sex, anal sex, vaginal sex, or no sexual activity) they engaged in the last 12 month prior to March 13, 2020. We use this date as it was the day after the World Health Organization Director-General Tedros Adhanom Ghebreyesus's declared COVID-19 COVID-19 a global pandemic as part of the Mission Brief opening remarks (Adhanom, 2020). Participants were also asked what types of sexual activity (oral sex, anal sex, vaginal sex, or no sexual activity) they engaged in the past 3 month since March 13, 2020. For each question, participants could select all sexual activities they engaged in.

\section{Sexual Partners}

If participants indicated they engaged in sexual activity, they were asked about the number of sexual partners they had in the last 12 month prior to March 13, 2020. Participants could type in any number of partners without limit. If a participant entered no partners, they were recoded as not having sex within this timeframe. The same question and procedure was followed for the number of sexual partners they had in the past 3 month since March 13, 2020.

\section{Analytic Plan}

Descriptive statistics were computed for participant sociodemographic characteristics (age, race and ethnicity, relationship status, living arraignment) and the outcome variables (type of sexual behavior and number of sexual partners). Prior to the bivariate analysis, all variables were collapsed as previously described. For the remaining analysis, the sample was stratified based on sexual orientation (gay, bisexual, or other sexual orientation cisgender men and lesbian, bisexual, or other sexual orientation cisgender women) and gender identity (transgender/genderqueer/gender non-conforming individuals). Multivariable analysis used multivariable logistic regression to test the relationship between the sociodemographic characteristics and type of sexual behavior and number of sexual partners. All analyses were conducted with SPSS version 23 (IBM Corporation, Armonk, New York).

\section{Results}

\section{Sample Characteristics}

The analytic sample consisted of 1090 participants who met the inclusion criteria. Table 1 describes the sociodemographic characteristics of the full sample as well as each of the three subsamples (gay, bisexual or other sexual orientation cisgender men, 
gay, bisexual or other sexual orientation cisgender women, and transgender and non-binary individuals of any sexual orientation). Of the participants, $43.9 \%(n=479)$ identified as gay or bisexual cisgender men, 36.7\% $(n=400)$ identified as lesbian or bisexual cisgender women, and $19.4 \%(n=211)$ identified as transgender and non-binary individuals.

\section{Independent Variables}

The majority of the participants in the study were between the ages of 18-29 (45.6\%, $n=497$, SD 11.85, M 33.88), and this trend holds across all sub-groups. The average age for gay or bisexual cisgender men was 32.8 (SD 13.07, M 36.63, Range 18-76), 36.6 for lesbian or bisexual women (SD 10.80, M32.76, Range 18-81), and 29.8 for transgender and non-binary individuals (SD 9.01, M 29.76, Range 18-70). The sample was primarily White Non-Hispanic $(69.0 \%, n=752)$. Similarly, this trend hold for all sub-groups with a slightly larger proportion of lesbian or bisexual cisgender women indicating they were White NonHispanic $(74.3 \%, n=297)$. For the full sample, there was approximately an even distribution between those who were married or in a domestic partnership $(27.2 \%, n=296)$, those in a committed relationship with out a legal status $(39.8 \%, n=434)$, and those who were single, separated, divorced, or widowed (33.0\%, $n=360$ ). Most of the sub-groups followed this pattern with the exception of gay and bisexual cisgender men where the majority were in a committed relationship $(42.0 \%, n=201)$. Lastly, the majority of the sample lived with their spouse or partner $(54.0 \%$, $n=589$ ). Again, this holds for all sub-groups although a larger proportion of transgender and non-binary individuals reported living with a non-romantic roommate or friend $(20.4 \%, n=43)$ compared to any other sub-group.

\section{Dependent Variables}

Only a quarter of participants reported engaging in any of the three sexual behaviors (oral, anal, or vaginal sex) in the 3 month prior to March 13, 2020. The most frequently reported sexual behavior was different for the sub-groups. Gay or bisexual cisgender men reported having anal sex as the most frequent sexual activity $(24.2 \%, n=165)$. Lesbian or bisexual cisgender women reported vaginal sex as the most frequent sexual activity $(25.5 \%, n=102)$. Finally, transgender and non-binary individuals reported no sexual activity as the most frequent sexual activity $(24.6 \%, n=52)$.

For the full sample, slightly over a quarter of all participants reported not having any sexual partners $(28.7 \%, n=313)$ and slightly more than half had only one partner $(51.2 \%, n=558)$. These patterns hold across all sub-groups with the exception of transgender and non-binary individuals where approximately equal halves of the sub-sample reported no sexual partners
$(43.6 \%, n=92)$ or one sexual partner $(48.3 \%, n=102)$. The average number of sexual partners for gay or bisexual cisgender men was 1.6 (SD 2.0, Range 0-20), 1.1 for lesbian or bisexual women (SD 1.1, Range 0-15), and 0.9 for transgender and non-binary individuals (SD 1.0, Range 0-10).

\section{Bivariate Analysis}

Table 2 presents the results of a paired samples $t$ test for the types of sexual behavior. It is also presented in Fig. 1. In the stratified analysis for gay or bisexual cisgender men, the number of people reporting having oral, anal, and vaginal sex (382 as compared to 101,331 as compared to 165,58 as compared to 29 , respectively, $p<.001$ ) decreased from the 12 month prior to March 13, 2020, and the 3 month after March 13, 2020. For lesbian or bisexual cisgender women, the numbers of people reporting having oral, anal, and vaginal sex (274 as compared to 74,77 as compared to 46, 250 as compared to 102 , respectively, $p<.001$ ) also decreased during the two time points. And finally, in the sub-group analysis for transgender and non-binary individuals, there were similar decreases in reported sexual activity for oral, anal, and vaginal sex (145 as compared to 38,67 as compared to 39,111 as compared to 51 , respectively, $p<.001$ ). It is important to note, while the first number covers a 12 month timeframe, the majority of our sample was married or in a committed relationship and cohabitating with their primary sexual partners. This means that although their primary sexual partner was available for sexual activity (i.e., no lockdown-related logistical barriers), the sexual partners chose not to engage in sex.

Table 2 also presents the results of a paired samples $t$ test for the number of sexual partners. It is also presented in Fig. 2. This compares the average number of sexual partners in the 3 month prior to March 13, 2020, and the 3 month after. For gay or bisexual cisgender men, the average number of sexual partners decreased from 2.67 partners (SD 6.21, Range $0-100, p<.001$ ) in the 3 month prior to March 13, 2020, to 1.61 partners (SD 2.05 , Range 0-20) in the 3 month after March 13, 2020. Similarly, lesbian or bisexual cisgender women reported a decrease in the average number of sexual partners, although this decrease was smaller. In the 3 month prior to March 13, 2020, this group had an average of 1.32 sexual partners (SD 1.07, Range 0-10, $p<.001$ ) as compared to an average of 1.13 sexual partners (SD 1.11 , Range $0-15$ ) in the 3 month after March 13, 2020. Finally, in the 3 month prior to March 13, 2020, transgender and nonbinary individuals reported an average of 1.36 sexual partners (SD 1.59, Range 0-15, $p<.001$ ). In the 3 month after March 13, 2020, the average number of sexual partners decreased to 0.94 (SD 1.00, Range 0-10).

\section{Multivariable Analysis}

Table 3 presents the results of the multivariable binary logistic regression models for engaging in sexual behavior (oral, anal, or 
Table 1 Sciodemographics for a sample of LGBTQ+individuals about COVID-19 pandemic, $n=1090$, 2020, USA

\begin{tabular}{|c|c|c|c|c|}
\hline & Full Sample $n=1090 \%(n)$ & $\begin{array}{l}\text { Gay, bisexual or other } \\
\text { sexual orientation cisgen- } \\
\text { der men } n=479 \%(n)\end{array}$ & $\begin{array}{l}\text { Lesbian, bisexual or other } \\
\text { sexual orientation cisgen- } \\
\text { der women } n=400 \%(n)\end{array}$ & $\begin{array}{l}\text { Transgender and non-binary } \\
\text { individuals (all sexual orien- } \\
\text { tations) } n=211 \%(n)\end{array}$ \\
\hline \multicolumn{5}{|c|}{ Sexual orientation and gender identity } \\
\hline Gay cisgender men & $36.4(397)$ & $36.4(397)$ & - & - \\
\hline $\begin{array}{l}\text { Bisexual or other sexual } \\
\text { orientation cisgender } \\
\text { men }\end{array}$ & $7.5(82)$ & $7.5(82)$ & - & - \\
\hline Lesbian cisgender women & $17.4(190)$ & - & $17.4(190)$ & - \\
\hline $\begin{array}{l}\text { Bisexual or other sexual } \\
\text { orientation cisgender } \\
\text { women }\end{array}$ & $19.3(210)$ & - & $19.3(210)$ & - \\
\hline $\begin{array}{l}\text { Transgender men (all } \\
\text { sexual orientations) }\end{array}$ & $4.5(49)$ & - & - & $4.5(49)$ \\
\hline $\begin{array}{l}\text { Transgender women (all } \\
\text { sexual orientations) }\end{array}$ & $3.4(37)$ & - & - & $3.4(37)$ \\
\hline $\begin{array}{l}\text { Non-binary (all sexual } \\
\text { orientations) }\end{array}$ & $11.5(125)$ & - & - & $11.5(125)$ \\
\hline Age & $\begin{array}{l}\text { (M 33.9, SD 11.9, Range } \\
\text { 18-81) }\end{array}$ & $\begin{array}{l}\text { (M 36.6 SD 13.1, Range } \\
\text { 18-76) }\end{array}$ & $\begin{array}{l}\text { (M 32.8 SD 10.8, Range } \\
\text { 18-81) }\end{array}$ & $\begin{array}{l}\text { (M 29.8 SD 9.0, Range } \\
\text { 18-70) }\end{array}$ \\
\hline $18-29$ & $45.6(497)$ & $37.4(179)$ & $48.0(192)$ & $59.7(126)$ \\
\hline $30-39$ & $31.8(347)$ & $32.8(157)$ & $33.0(132)$ & $27.5(58)$ \\
\hline $40-49$ & $10.1(110)$ & $10.6(51)$ & $10.5(24)$ & $8.1(17)$ \\
\hline 50 and older & $12.5(136)$ & $19.2(92)$ & $8.5(34)$ & $4.7(10)$ \\
\hline \multicolumn{5}{|l|}{ Race/Ethnicity } \\
\hline White non-Hispanic & $69.0(752)$ & $64.3(308)$ & $74.3(297)$ & $69.7(147)$ \\
\hline Black non-Hispanic & $11.1(121)$ & $15.2(73)$ & $9.0(36)$ & $5.7(12)$ \\
\hline Latinx & $9.5(104)$ & $9.6(46)$ & $8.3(33)$ & $11.8(25)$ \\
\hline $\begin{array}{l}\text { Asian, Pacific Islander, or } \\
\text { Native American Non- } \\
\text { Hispanic }\end{array}$ & $10.3(113)$ & $10.9(52)$ & $8.5(34)$ & $12.8(27)$ \\
\hline \multicolumn{5}{|l|}{ Relationship status } \\
\hline $\begin{array}{l}\text { Married/domestic partner- } \\
\text { ship }\end{array}$ & $27.2(296)$ & $25.9(124)$ & $30.5(122)$ & $23.7(50)$ \\
\hline $\begin{array}{l}\text { In a committed relation- } \\
\text { ship }\end{array}$ & $39.8(434)$ & $42.0(201)$ & $39.0(156)$ & $36.5(77)$ \\
\hline $\begin{array}{l}\text { Single/separated /divorced/ } \\
\text { widowed }\end{array}$ & $33.0(360)$ & $32.2(154)$ & $30.5(122)$ & $39.8(84)$ \\
\hline \multicolumn{5}{|l|}{ Living arrangement ${ }^{\mathrm{a}}$} \\
\hline Partner/spouse & $54.0(589)$ & $55.9(268)$ & $56.8(227)$ & $44.5(94)$ \\
\hline Alone & $12.2(133)$ & $14.4(69)$ & $9.8(39)$ & $11.8(25)$ \\
\hline $\begin{array}{l}\text { Non-romantic roommate/ } \\
\text { friend }\end{array}$ & $13.8(150)$ & $13.6(65)$ & $10.5(42)$ & $20.4(43)$ \\
\hline Family & $18.0(196)$ & $14(67)$ & $21.3(85)$ & $20.9(44)$ \\
\hline Missing & $2.0(22)$ & $2.1(10)$ & $1.8(7)$ & $2.4(5)$ \\
\hline \multicolumn{5}{|c|}{ Sexual behaviors in the past 3 month since march $13 t^{a}$} \\
\hline oral sex & $19.5(213)$ & $21.1(101)$ & $18.5(74)$ & $18.0(38)$ \\
\hline Anal sex & $22.9(250)$ & $24.2(165)$ & $11.5(46)$ & $18.5(39)$ \\
\hline Vaginal sex & $16.7(182)$ & $6.1(29)$ & $25.5(102)$ & $24.2(51)$ \\
\hline $\begin{array}{l}\text { No sex in the past } 12 \\
\text { month }\end{array}$ & $14.2(115)$ & $7.1(34)$ & $17.3(69)$ & $24.6(52)$ \\
\hline \multicolumn{5}{|c|}{ Number of sexual partners in the past 3 month since march 13th } \\
\hline No sexual partners & $28.7(313)$ & $21.1(101)$ & $30.1(120)$ & $43.6(92)$ \\
\hline One sexual partner & $51.2(558)$ & $49.1(67)$ & $55.3(221)$ & $48.3(102)$ \\
\hline
\end{tabular}


Table 1 (continued)

\begin{tabular}{lllll}
\hline & Full Sample $n=1090 \%(n)$ & $\begin{array}{l}\text { Gay, bisexual or other } \\
\text { sexual orientation cisgen- } \\
\text { der men } n=479 \%(n)\end{array}$ & $\begin{array}{l}\text { Lesbian, bisexual or other } \\
\text { sexual orientation cisgen- } \\
\text { der women } n=400 \%(n)\end{array}$ & $\begin{array}{l}\text { Transgender and non-binary } \\
\text { individuals (all sexual orien- } \\
\text { tations) } n=211 \%(n)\end{array}$ \\
\hline Two sexual partners & $11.8(129)$ & $15.2(73)$ & $10.8(43)$ & $6.2(13)$ \\
Three sexual partners & $3.3(36)$ & $6.1(29)$ & $1.3(4)$ & $0.9(2)$ \\
Four sexual partners & $2.0(22)$ & $3.5(17)$ & $1.3(4)$ & $0(0)$ \\
Five sexual partners & $1.4(15)$ & $2.5(12)$ & $0.5(2)$ & $0.5(1)$ \\
Six or more sexual partners & $1.2(13)$ & $2.0(10)$ & $0.5(2)$ & $0.5(1)$ \\
Missing & $0.4(4)$ & $0.4(2)$ & $0.5(2)$ & $0(0)$ \\
\hline
\end{tabular}

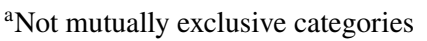

vaginal) in the 3 month after March 13, 2020. For this analysis, any reported sexual activity (oral, anal, or vaginal) was collapsed into a dichotomous variable of having had sex or not having had sex. The model for gay or bisexual cisgender men was statistically significant $\left(\chi^{2}(5)=32.03, p<.001\right)$ with Naglekerke $R^{2}=8.8 \%$. In the adjusted model, the odds of reporting having sex were higher for cisgender gay and bisexual men between the ages of $30-39$ ( $\mathrm{AOR}=2.02,95 \%$ CI $1.14-3.56, p=.016)$, those living with a partner or spouse (AOR $=2.20,95 \%$ CI $1.12-4.33$, $p=.023$ ), and those living with a non-romantic roommate or friend $(\mathrm{AOR}=2.88,95 \% \mathrm{CI} 1.39-5.94, p=.004)$.

The model for lesbian or bisexual cisgender women was statistically significant $\left(\chi^{2}(5)=53.81, p<.001\right)$ with Naglekerke $R^{2}=17.3 \%$. Cisgender lesbian and bisexual women had higher odds of having sex if they were married or in a domestic partner$\operatorname{ship}(\mathrm{AOR}=4.54,95 \%$ CI $1.95-10.59, p<.001)$, in a committed relationship $(\mathrm{AOR}=3.54,95 \% \mathrm{CI} 1.74-7.22, p=.001)$, or living with their partner or spouse $(\mathrm{AOR}=2.14,95 \%$ CI $1.02-4.49$, $p=.044)$.

Finally, the model for transgender and non-binary individuals was statistically significant $\left(\chi^{2}(5)=51.50, p<.001\right)$ with Naglekerke $R^{2}=30.9 \%$. The findings for this sub-group were similar to the findings for cisgender women. Transgender and non-binary individuals had higher odds of having sex if they were married or in a domestic partnership (AOR $=9.97,95 \%$ CI 13.05-32.59, $p<.001)$ or in a committed relationship (AOR $=8.46,95 \% \mathrm{CI}$ $3.11-23.04, p<.001)$.

Table 4 presents the results of the multivariable logistic regression models for the number of sexual partners in the 3 month after March 13, 2020. For this analysis, the number of partners was collapsed into dichotomous groups zero or one sexual partner, and two or more sexual partners. The model for gay or bisexual cisgender men did not have any significant findings. The model for lesbian or bisexual cisgender women was statistically significant $\left(\chi^{2}(5)=58.57, p<.001\right)$ with Naglekerke $R^{2}=19.6 \%$. In the adjusted model, the odds of having two or more partners was lower among cisgender women in committed relationships $(\mathrm{AOR}=0.31,95 \% \mathrm{CI} 0.16-0.59, p<.001)$ and those living with a partner or spouse $(\mathrm{AOR}=0.30,95 \%$ CI $0.13-0.65, p=.002)$.
The model for transgender and non-binary individuals was statistically significant $\left(\chi^{2}(5)=51.50, p<.001\right)$ with Naglekerke $\mathrm{R}^{2}=30.9 \%$. The sub-group analysis for transgender and nonbinary individuals had similar findings. The odds of having two or more partners was lower among transgender and non-binary individuals in a committed relationship ( $\mathrm{AOR}=0.26,95 \% \mathrm{CI}$ $0.10-0.66, p=.004$ ) and those living with a partner or a spouse $(\mathrm{AOR}=0.25,95 \%$ CI $0.07-0.86 p=.028)$.

\section{Discussion}

This study contributes to the emerging literature on the effects of the COVID-19 pandemic on interpersonal relationships, specifically on the sexual lives of LGBTQ+individuals.

The analysis presented here indicates that among LGBTQ people, there is a diversity of experiences around sexual activities, suggesting tailored approaches to harm reduction messaging is warranted. This is especially critical when "pandemic fatigue" is prevalent (Zhao et al., 2020), and LGBTQ people as a population are more likely to already experience pre-pandemic socioeconomic inequalities that are exacerbated by the ongoing pandemic (Gibb et al., 2020). It is important to note that is impossible to attribute changes in sexual activity and number of sexual partners to any one factor, as a multitude of interrelated factors likely contribute to such changes, including the desire to protect the health of loved ones, mental health challenges, stay-at-home orders, and specific messaging on hookup apps or by local health departments. However, this study provides some actionable findings that can help form the basis of public health messaging to LGBTQ communities.

Overall, sexual activity and number of sexual partners decreased after March 13, 2020 for LGBTQ people, particularly for gay and bisexual men but across all sub-groups. First, among a sample of 1051 sexual minority men, a recent study found that the majority of participants reported fewer sexual partners and fewer opportunities to have sex (Sanchez et al., 
Table 2 Sexual behaviors and number of sexual partners before and during the COVID-19 pandemic by sexual orientation and gender identity, $\mathrm{n}=1090,2020$, USA

Last 12 month prior to march 13th \% (n) Last 3 month since march 13th $\%(n)$ t-statistic, $p$-value

Gay, bisexual or other sexual orientation cisgender men $n=479$

Sexual behaviors ${ }^{\mathrm{a}}$

$\begin{array}{ll}\text { Oral sex } & 79.7(382) \\ \text { Anal sex } & 69.1(331) \\ \text { Vaginal sex } & 12.1(58) \\ \text { No sex in the past } 12 \text { month } & 7.1(34) \\ \text { Number of sexual partners in the last } 3 & (\text { M 2.7 SD 6.2 Range 0-100) } \\ \text { month } & 12.1(58) \\ \text { No sexual partners } & 45.7(219) \\ \text { One sexual partner } & 19.4(93) \\ \text { Two sexual partners } & 8.6(41) \\ \text { Three sexual partners } & 4.0(19) \\ \text { Four sexual partners } & 3.5(17) \\ \text { Five sexual partners } & 5.7(28) \\ \text { Six or more sexual partners } & 0.8(4) \\ \text { Missing } & \end{array}$

Lesbian, bisexual or other sexual orientation cisgender women $n=400$

Sexual behaviors ${ }^{\mathrm{a}}$

$\begin{array}{ll}\text { Oral sex } & 68.5(274) \\ \text { Anal sex } & 19.3(77) \\ \text { Vaginal sex } & 62.5(250) \\ \text { No sex in the past } 12 \text { month } & 17.3(69) \\ \text { Number of sexual partners in the last } 3 & (\text { M } 1.3 \text { SD 1.1, Range 0-10) } \\ \text { month } & \\ \text { No sexual partners } & 24.1(96) \\ \text { One sexual partner } & 56.3(225) \\ \text { Two sexual partners } & 13.3(53) \\ \text { Three sexual partners } & 2.5(10) \\ \text { Four sexual partners } & 1.8(7) \\ \text { Five sexual partners } & 0.5(2) \\ \text { Six or more sexual partners } & 1.4(5) \\ \text { Missing } & 0.5(2)\end{array}$

Transgender and non-binary individuals (all sexual orientations) $n=211$

Sexual behaviors ${ }^{\mathrm{a}}$

$\begin{array}{ll}\text { Oral sex } & 68.7(145) \\ \text { Anal sex } & 31.8(67) \\ \text { Vaginal sex } & 52.6(111) \\ \text { No sex in the past } 12 \text { month } & 24.6(52) \\ \text { Number of sexual partners in the last } 3 & (\text { M } 1.4 \text { SD } 1.6 \\ \text { month } & \\ \text { No sexual partners } & 34.6(73) \\ \text { One sexual partner } & 49.3(104) \\ \text { Two sexual partners } & 8.5(18) \\ \text { Three sexual partners } & 3.3(7) \\ \text { Four sexual partners } & 2.4(5) \\ \text { Five sexual partners } & 0.9(2) \\ \text { Six or more sexual partners } & 0.9(2) \\ \text { Missing } & 0(0)\end{array}$

$21.1(101)$

$24.2(165)$

$6.1(29)$

7.1 (34)

(M 1.6, SD 2.0, Range 0-20)

$21.1(101)$

$49.1(67)$

$15.2(73)$

$6.1(29)$

3.5 (17)

$2.5(12)$

$2.0(10)$

$0.4(2)$

$18.5(74)$
$11.5(46)$
$25.5(102)$
$17.3(69)$
M $1.1, \mathrm{~S}$
$30.1(120)$
$55.3(221)$
$10.8(43)$
$1.3(4)$
$1.3(4)$
$0.5(2)$
$0.5(2)$
$0.5(2)$

$18.0(38)$

$18.5(39)$

$24.2(51)$

$24.6(52)$

(M 0.9, SD 1.0, Range 0-10)

$43.6(92)$

48.3 (102)

$6.2(13)$

$0.9(2)$

$0(0)$

0.5 (1)

$0.5(1)$

$0(0)$

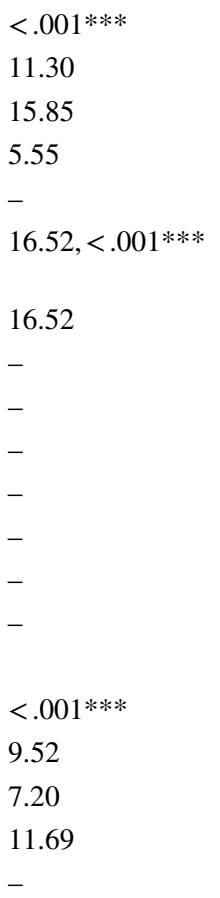

$18.48,<.001 * * *$

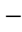

$-$

-

-

$-$

$-$

21.48

6.90

8.18

$-$

$11.84,<.001 * * *$

$-$

$-$

$-$

$-$

$-$

$-$

$-$

${ }^{\mathrm{a}}$ Not mutually exclusive categories

$* p<.05, * * p<.01, * * * p<0.001$ 

and during the COVID-19 pandemic by sexual orientation and gender identity, $n=1090$, 2020, USA
Fig. 1 Sexual behaviors before

\section{Changes in Sexual Behavior by \\ Sexual Orientation \& Gender Identity}

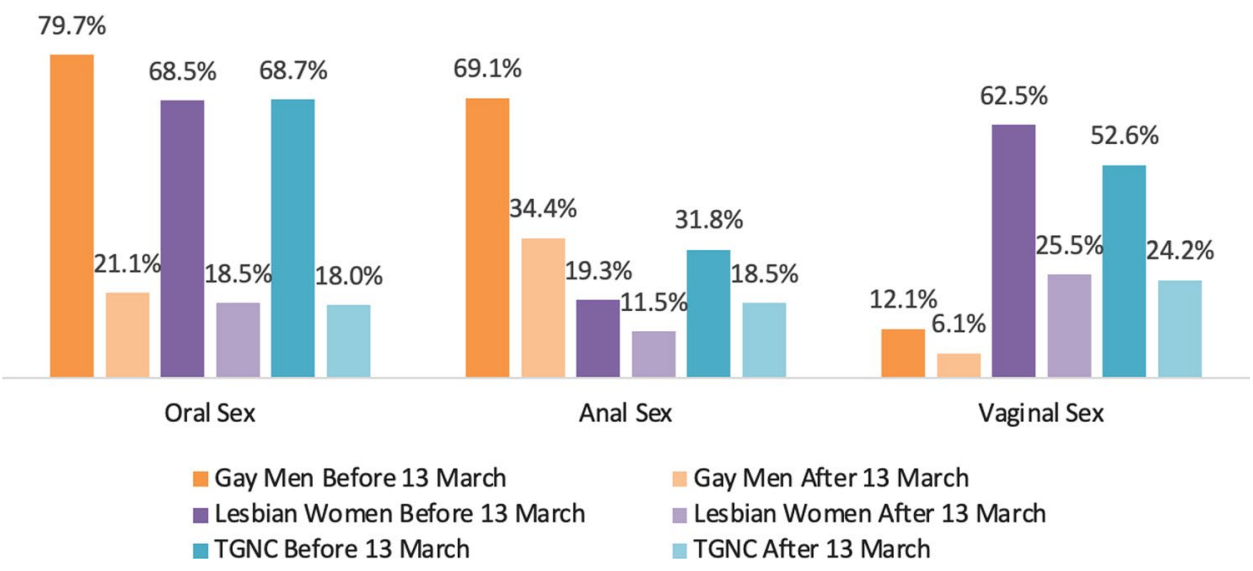

Fig. 2 Number of sexual partners before and during the COVID-19 pandemic by sexual orientation and gender identity, $n=1090,2020$, USA

Changes in Average Number of Sexual Partners by Sexual Orientation \& Gender Identity

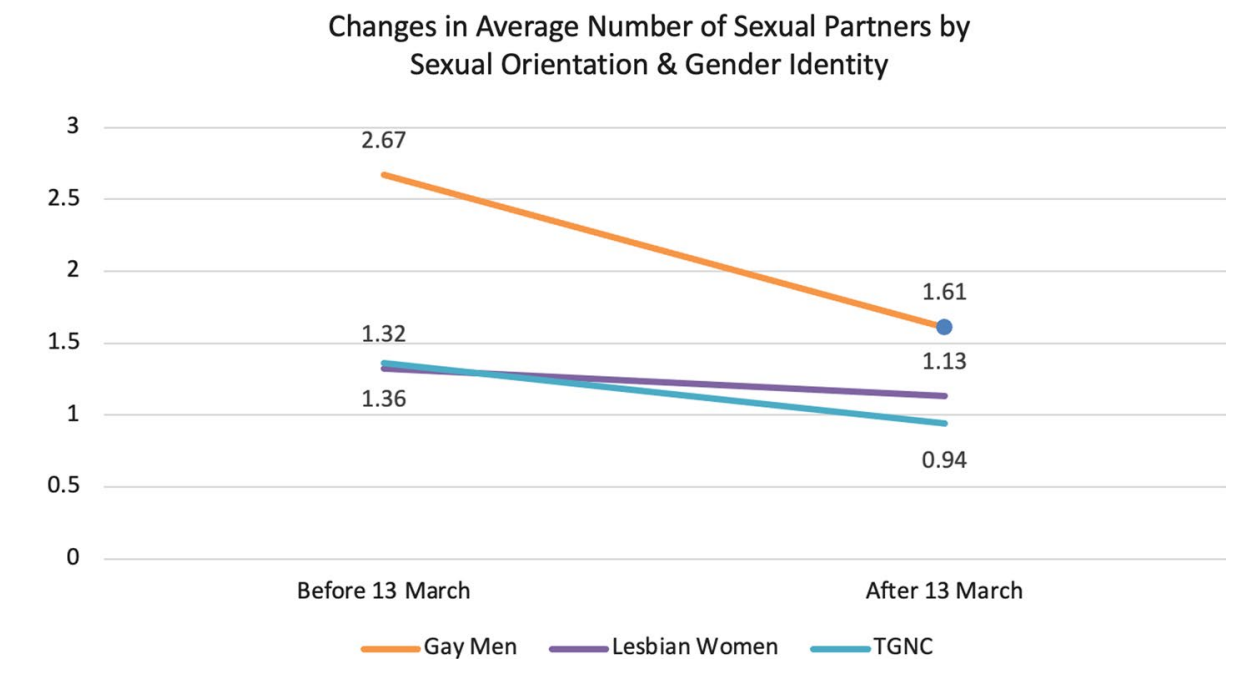

2020). Similarly, in a sample of 728 sexual minority men surveyed in spring 2020, researchers found that participants $90 \%$ of the sample reported either one or zero sexual partners in the previous 30 days, representing a significant decrease for many (notably, participants reported changes in their sexual activities with partners, including virtual sex, suggesting individuals are concerned about COVID-related risks posed by sexual activity (McKay et al., 2020). Echoing these same finding, in a study of 455 SMM surveyed in May 2020, researchers found that the number of casual partners remained steady, but condomless anal sex declined significantly. The study also found that while substance use and condomless anal sex decreased during this time period, the association between sexual behavior and substance use was in fact amplified, suggesting increased risk for both COVID-19 and HIV transmission (Starks et al., 2020). However, other research departs from these findings, including a recent online study that found increased sexual activity among a sample size of 518 sexual minority men (Stephenson et al., 2020). Specifically, the data indicated a mean increase in 2.3 sexual partners, a mean increase in 2.1 anal sex partners specifically, and a very small increase in condomless and/or PrEP-less anal sex partners during spring 2020. Moreover, increases in sexual behaviors were associated with substance use during this same time frame. The authors note that it is critical to provide comprehensive sexual health and HIV prevention services during the pandemic, suggesting an increase in telehealth-delivered care is urgently needed (Stephenson et al., 2020). Similarly, another US-based study found that those reporting a new sex partner in the past 30 days were more likely to be over 30 years old, Latinx, and unsure if they had been in close contact with someone who tested positive for COVID-19 (Grov et al., 2021). Overall, these varied findings suggest that the impacts of COVID-19 on sexual behaviors are likely not static, may differ significantly depending on how effectively the pandemic is being controlled in a given context, and influenced by myriad other factors that warrant further research.

Reflecting the overall literature on sexual and gender minority people, there is significantly less known about how the 


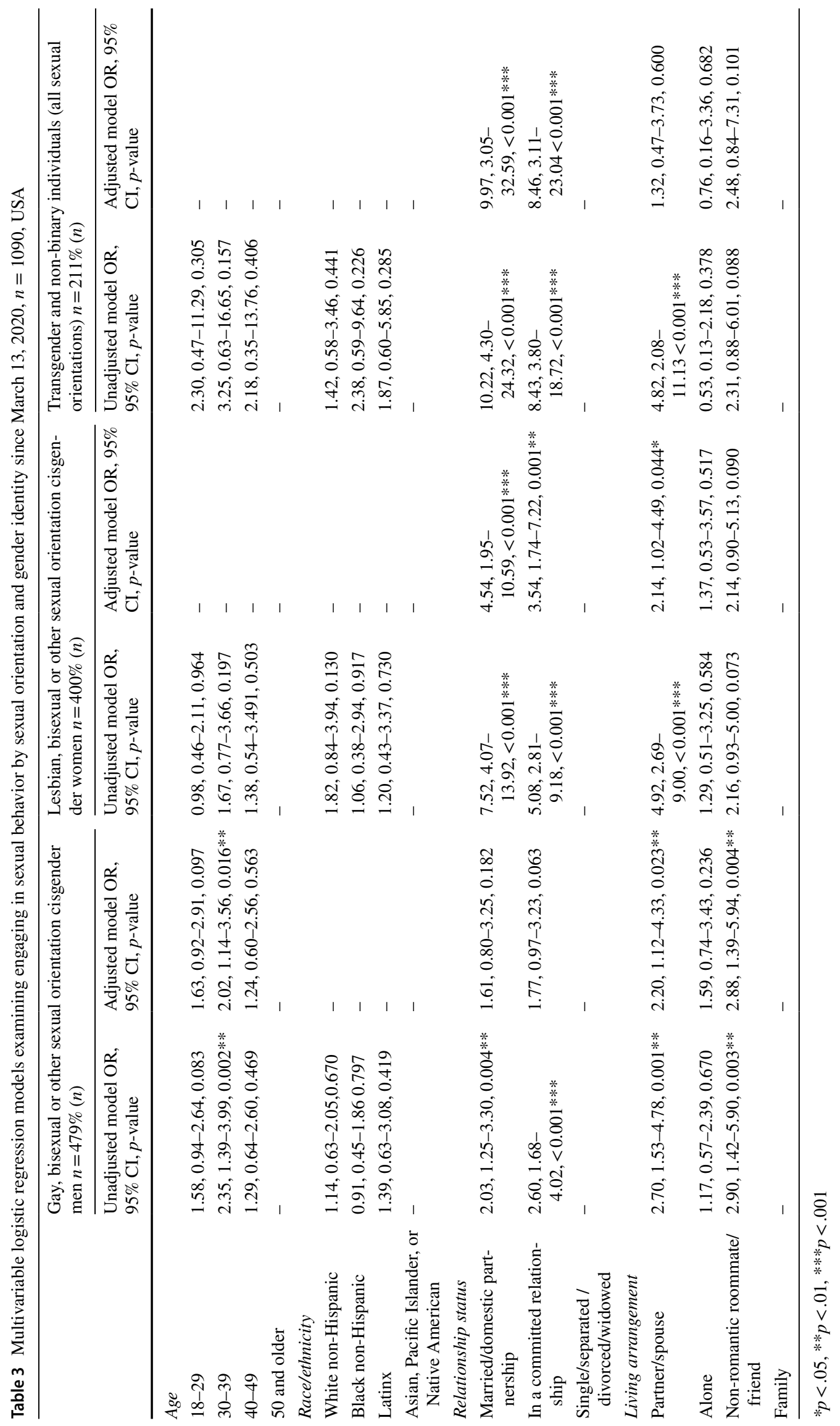


Table 4 Multivariable logistic regression models examining number of partners by sexual orientation and gender identity since March 13, 2020, $n=1090$, USA

\begin{tabular}{|c|c|c|c|c|c|c|}
\hline & \multicolumn{2}{|c|}{$\begin{array}{l}\text { Gay, bisexual or other sexual orienta- } \\
\text { tion cisgender men } n=479 \%(n)\end{array}$} & \multicolumn{2}{|c|}{$\begin{array}{l}\text { Lesbian, bisexual or other sexual orienta- } \\
\text { tion cisgender women } n=400 \%(n)\end{array}$} & \multicolumn{2}{|c|}{$\begin{array}{l}\text { Transgender and non-binary individu- } \\
\text { als (all sexual orientations) } n=211 \% \\
(n)\end{array}$} \\
\hline & $\begin{array}{l}\text { Unadjusted model } \\
\text { OR, } 95 \% \mathrm{CI}, \\
p \text {-value }\end{array}$ & $\begin{array}{l}\text { Adjusted model } \\
\text { OR, } 95 \% \mathrm{CI}, \\
p \text {-value }\end{array}$ & $\begin{array}{l}\text { Unadjusted model } \\
\text { OR, 95\% CI, } p \text {-value }\end{array}$ & $\begin{array}{l}\text { Adjusted model } \\
\text { OR, 95\% CI, } \\
p \text {-value }\end{array}$ & $\begin{array}{l}\text { Unadjusted model } \\
\text { OR, } 95 \% \mathrm{CI}, \\
p \text {-value }\end{array}$ & $\begin{array}{l}\text { Adjusted model } \\
\text { OR, 95\% CI, } \\
p \text {-value }\end{array}$ \\
\hline \multicolumn{7}{|l|}{ Age } \\
\hline $18-29$ & $\begin{array}{l}0.77,0.45-1.30 \\
0.323\end{array}$ & - & $\begin{array}{r}0.82,0.38- \\
1.81,0.629\end{array}$ & - & $\begin{array}{l}0.81,0.22-3.00 \\
0.747\end{array}$ & - \\
\hline $30-39$ & $\begin{array}{l}1.17,0.69-1.99 \\
0.553\end{array}$ & - & $\begin{array}{r}1.05,0.47- \\
2.35,0.912\end{array}$ & - & $\begin{array}{l}0.57,0.14-2.29 \\
0.430\end{array}$ & - \\
\hline $40-49$ & $\begin{array}{l}0.73,0.35-1.51 \\
0.399\end{array}$ & - & $\begin{array}{l}1.00,0.38-2.63 \\
0.999\end{array}$ & - & $\begin{array}{l}0.63,0.12-3.22 \\
0.574\end{array}$ & - \\
\hline 50 and older & - & - & - & - & - & - \\
\hline \multicolumn{7}{|l|}{ Race/ethnicity } \\
\hline $\begin{array}{l}\text { White non-His- } \\
\text { panic }\end{array}$ & $\begin{array}{l}1.43,0.76-2.69 \\
0.266\end{array}$ & - & $\begin{array}{r}0.63,0.30- \\
1.30,0.208\end{array}$ & - & $\begin{array}{l}1.30,0.53-3.17 \\
0.565\end{array}$ & - \\
\hline $\begin{array}{l}\text { Black non-His- } \\
\text { panic }\end{array}$ & $\begin{array}{l}1.32,0.62-2.82 \\
0.471\end{array}$ & - & $\begin{array}{r}0.63,0.24- \\
1.68,0.355\end{array}$ & - & - & - \\
\hline Latinx & $\begin{array}{r}0.89,0.37- \\
2.12,0.786\end{array}$ & - & $\begin{array}{l}0.71,0.26-1.93 \\
0.508\end{array}$ & - & $\begin{array}{l}1.34,0.42-4.27 \\
0.625\end{array}$ & - \\
\hline $\begin{array}{l}\text { Asian, Pacific } \\
\text { Islander, or } \\
\text { native American }\end{array}$ & - & - & - & - & - & - \\
\hline \multicolumn{7}{|l|}{ Relationship status } \\
\hline $\begin{array}{l}\text { Married/domestic } \\
\text { partnership }\end{array}$ & $\begin{array}{l}0.76,0.47-1.26 \\
0.290\end{array}$ & - & $\begin{array}{l}0.24,0.14- \\
0.41,<0.001 * * *\end{array}$ & $\begin{array}{l}0.62,0.26-1.52 \\
0.298\end{array}$ & $\begin{array}{l}0.16,0.07- \\
0.36,<0.001 * * *\end{array}$ & $\begin{array}{l}0.60,0.16-12.17, \\
0.443\end{array}$ \\
\hline $\begin{array}{l}\text { In a committed } \\
\text { relationship }\end{array}$ & $\begin{array}{l}0.93,0.61-1.44 \\
0.751\end{array}$ & - & $\begin{array}{l}0.18,0.10- \\
0.300,<0.001 * * *\end{array}$ & $\begin{array}{l}0.31,0.16-0.59 \\
0.001^{* * *}\end{array}$ & $\begin{array}{l}0.12,0.06- \\
0.26,<0.001 * * *\end{array}$ & $\begin{array}{l}0.26,0.1-0.66 \\
0.004 * *\end{array}$ \\
\hline $\begin{array}{l}\text { Single/separated / } \\
\text { divorced/wid- } \\
\text { owed }\end{array}$ & - & - & - & - & - & - \\
\hline \multicolumn{7}{|l|}{ Living arrangement } \\
\hline Partner/spouse & $\begin{array}{l}0.71,0.41-1.23 \\
0.220\end{array}$ & - & $\begin{array}{l}0.20,0.12-0.35 \\
* * *<0.001\end{array}$ & $\begin{array}{l}0.30,0.134-0.65 \\
0.002 * *\end{array}$ & $\begin{array}{l}0.14,0.06- \\
0.35<0.001 * * *\end{array}$ & $\begin{array}{l}0.25,0.07-0.86 \\
0.028^{*}\end{array}$ \\
\hline Alone & $\begin{array}{l}0.90,0.45-1.79 \\
0.754\end{array}$ & & $\begin{array}{l}0.52,0.24-1.14 \\
0.101\end{array}$ & $\begin{array}{l}0.50,0.220-1.12 \\
0.090\end{array}$ & $\begin{array}{l}1.30,0.49-3.48 \\
0.601\end{array}$ & $\begin{array}{l}1.15,0.41-3.18, \\
0.794\end{array}$ \\
\hline $\begin{array}{l}\text { Non-romantic } \\
\text { roommate/friend }\end{array}$ & $\begin{array}{l}1.35,0.68-2.69 \\
0.393\end{array}$ & - & $\begin{array}{l}0.90,0.42-1.86 \\
0.755\end{array}$ & $\begin{array}{l}0.94,0.44-2.03 \text {, } \\
0.872\end{array}$ & $\begin{array}{l}1.52,0.65-3.53 \\
0.335\end{array}$ & $\begin{array}{l}1.66,0.68-4.01, \\
0.264\end{array}$ \\
\hline Family & - & - & - & - & - & - \\
\hline
\end{tabular}

$* p<.05, * * p<.01, * * * p<.001$

pandemic has affected the sexual behaviors of sexual minority women and transgender people. In addition to concerns about COVID-19 risks, the finding that sexual activity was decreased among lesbian and bisexual women may also reflect disproportionate burden on women due to increased childcare challenges (Sevilla \& Smith, 2020) and higher likelihood of losing one's job in comparison to men (Alon, Doepke, Olmstead-Rumsey, \& Tertilt, 2020; Power, 2020). For transgender individuals, this finding may reflect exacerbated inequalities that existed prior to the pandemic, such as higher rates of mental health challenges, lower socioeconomic status/more likely to experience poverty, and more job instability (Badgett et al., 2019; Su et al., 2016). More research is needed to identify the unique factors that shape these populations' sexual decision-making during the pandemic. Finally, the study presented here also found that being married or in a committed relationship was associated with more sexual activity for all sub-groups. Similarly, for gay and bisexual men, living with a non-romantic roommate or friend was also associated with more sexual activity. Although these sub-groups reported higher levels of sexual activity compared to unpartnered participants, it is important to note that even partnered individuals reported an overall decrease in sexual activity 
during this time period, suggesting the complex impact of the pandemic has widely affected people's sexual behaviors and sexual relationships.

\section{Implications for Public Health Practice}

LGBTQ people, for whom social isolation, lack of family support, mental health challenges, economic instability and suicide rates are already high (Badgett et al., 2019; Centers for Disease Control \& Prevention, 2016; Mccrone, 2018), may be placed at increased risk for isolation-related health outcomes (Salerno et al., 2020). Engaging in sexual activity with a partner is one strategy to reduce insolation and thereby mitigate isolation-related health outcomes. Thus, it is important to not only tailor COVID-related sexual health messaging to various sub-groups within the LGBTQ communities, but also place a clear emphasis on harm reduction strategies that eschew shame-based approaches. Specifically, the findings presented here may inform the development of clinical practice and public health guidelines related to decision-making around engaging in sexual activity during a global pandemic, particularly in settings where transmission is not well-controlled, such as the USA

\section{Non-shame-Based Harm Reduction Approaches}

As the pandemic did not abate in the USA as in many other countries (World Health Organization, 2010), news outlets and social media have indicated that people have begun to re-engage in social and sexual activities which leads many to flout measures they initially took seriously (Bosman et al., 2020). It is thus critical to promote non-shamed-based harm reduction strategies that mitigate COVID risk (Yong, 2020), as well as risk of STIs and HIV, thereby making inevitable behavior less unsafe. Previous studies on pre-exposure prophylaxis (PrEP) uptake among sexual minority men and transgender women provide a template for effective messaging as well as messaging to avoid. Recent HIV prevention research has suggested risk-based messaging around PrEP is stigmatizing and ultimately undermines PrEP uptake among communities most in need of HIV prevention efforts (Calabrese, 2020). Applied to COVID-related sexual behavior messaging, it would also be prudent to develop and normalize non-shamed-based harm reduction approaches to making sexual behaviors during COVID as safe as possible (Newman \& Guta, 2020).

\section{Subgroup-Specific Messaging}

This study also provides a basis for specific messaging for those who are engaging in sexual activity, especially if they are not in a monogamous cohabitating relationship. Recent studies have found partners are engaging in more diverse sexual experiences such as sexting, sharing sexual fantasies, and trying new positions (Banerjee \& Rao, 2020; Lehmiller et al., 2021; Lopes et al., 2020). Messages that incorporate these suggestions can help individuals make decisions that reduce their risk of viral transmission when engaging in sexual activity during an ongoing pandemic. The New York City Department of Health and Hygiene released a "Safer Sex and COVID-19" document that provided guidelines for engaging in sexual activity as safely as possible during the pandemic. One of the suggestions included, "Make it a little kinky. Be creative with sexual positions and physical barriers, like walls, that allow sexual contact while preventing close face to face contact" (New York City Department of Health \& Mental Hygiene, 2020). In a document aimed at keeping sex workers as safe as possible, the British Columbia Ministry of Health also recommended the use of "glory holes" to avoid COVID-19 exposure (British Columbia Ministry of Health, 2020). Researchers have called for the USA to widely adopt and promote these guidelines in order to meet the needs of both sex workers and other individuals that are engaging in sexual behaviors with persons outside of their household (Singer et al., 2020).

\section{Opportunity to Enhance HIV and STI Prevention Efforts Alongside COVID Precautions}

Finally, helping individuals create a dialogue around testing, risk negotiation, and disclosure as it relates to COVID-19 may have more far-reaching implications by enhancing HIV and STI prevention. As noted above, some COVID-related studies have documented an increase in behaviors that put individuals at higher risk for HIV (Starks et al., 2020), suggesting now is the time for more, rather than less, programming around HIV (Newman \& Guta, 2020). Researchers have recently called for increased efforts to address SMM's concerns about both COVID-19 and HIV transmission, and to provide "nuanced public health messages for GBMSMs that convey the ongoing simultaneous health threats of both HIV and COVID-19" (Stephenson et al., 2020). Indeed, since conversations about COVID-19 safety may closely mirror the conversations individuals would have around STIs and HIV, the COVID-19 pandemic has provided an opportunity to practice these conversations in a potentially less stigmatizing context and to energize efforts to encourage open conversations among sexual partners.

\section{Limitations}

There were several limitations to this study. This study was conducted over the internet and although there was a thorough data cleaning process it is possible that some of the participants took the survey multiple times. It is also possible that internet bots completed the survey despite our attempts to prevent bots from accessing the survey and identifying their responses if they were able to access the survey. Second, the majority of our sample is 
comprised of participants who identify as white and limits the generalizability of our finding. Efforts were made to recruit participants of color by conducting outreach to online communities of color; however, recruitment efforts were not as successful in these virtual communities due to legacies of medical mistrust. In the future, recruitment efforts should begin with more focused efforts to enroll participants of color thereby allowing for community building between the research staff and these communities. Third, although this is a national survey, the cross-sectional study design does not allow for causal inference. Fourth, the recall window for sexual activity is not of the same 3-month duration. Although the WHO declared COVID-19 a pandemic on March 12, 2020, the epidemic status of COVID-19 began with the outbreak in December 2019. Using a recall window of 3 month prior to March 13, 2020, would mean participants were reporting sexual behaviors under the case definition of an epidemic and would not truly capture a pre-COVID-19 data. A prompt asking about sexual behaviors during the same time the previous year (i.e., 3 month after March 13, 2019) would have introduced both recall bias and social desirability bias, including the likely over-reporting of sexual activity. Therefore, the timeframe of the previous year was deemed to be the best despite the difference in the timeframe of the recall window. Fifth, social desirability bias is likely present as the survey instrument collected information about sexual behaviors and number of sexual partners. The omnipresent nature of COVID-19 social distancing messages would make it all but impossible to not be aware of the need to reduce the number of social and by extension, sexual contacts. Therefore, it is likely that the number of sexual partners was underreported in the period after March 13, 2021. Despite these limitations, this study provides insight into the effect of COVID-19 on the sexual relationships of LGBTQ+ participants. Finally, it is impossible to attribute the reduced sexual activity and number of sexual partners to any one factor and is likely attributed to a complex interplay of the desire to protect the health of those close family members, mental health challenges, stayat-home orders, and specific messaging on hookup apps or by local health departments.

\section{Future Research Directions}

As the majority of research on LGBTQ people often focuses on sexual minority men, more studies are needed to better elucidate the unique needs of sexual minority women and transgender people. Additionally, longitudinal research is needed to examine COVID-related changes in sexual behaviors over time, as the pandemic has continued beyond the initial studies conducted at the beginning of the outbreak in the early month of 2020. Finally, as noted in the limitations, there is a multitude of likely interrelated factors that have contributed to significant changes in sexual behaviors during the COVID-19 pandemic. Further examining these various factors, such as mental health, financial stability and substance use, will provide more data on which to base tailored messaging and programming that support LGBTQ people.

\section{Conclusions}

Although the entirety of social impacts of COVID-19 remain to be seen, the findings presented here suggest that within the LGBTQ population, there is a diversity of experiences around sexual activity, warranting tailored messaging. As with other pandemics, notably the HIV pandemic which continues around the world, non-shamed-based harm reduction is critical to reducing viral transmission, particularly among those placed at highest risk for COVID acquisition. In addition to reducing COVID-19 and STI/HIV risks, tailored approaches are critical to avoid exacerbating mental health disparities among LGBTQ people.

Funding This study was funded by discretionary funding from the Center for Health, Identity, Behavior and Prevention Studies at Rutgers University.

\section{Declarations}

Conflict of interest There are no conflicts of interest to report for any of the authors.

Informed Consent Informed consent was obtained from all individual participants included in the study.

\section{References}

Adhanom, T. (2020). WHO Director-General's opening remarks at the Mission briefing on COVID-19: 12 March 2020 [Press release]. Retrieved from https://www.who.int/director-general/speeches/ detail/who-director-general-s-opening-remarks-at-the-missionbriefing-on-covid-19---12-march-2020.

Alon, T. M., Doepke, M., Olmstead-Rumsey, J., \& Tertilt, M. (2020). The impact of COVID-19 on gender equality (0898-2937). Retrieved from https://www.nber.org/papers/w26947.

Alpalhão, M., \& Filipe, P. (2020). The impacts of isolation measures against SARS-CoV-2 infection on sexual health [Editorial]. AIDS and Behavior, 24, 2258-2259.

Badgett, M. L., Choi, S. K., \& Wilson, B. D. (2019). LGBT poverty in the United States. Retrieved from Los Angeles, CA: http://willi amsinstitute.law.ucla.edu/wp-content/uploads/National-LGBTPoverty-Oct-2019.pdf.

Banerjee, D., \& Nair, V. S. (2020). "The untold side of COVID-19": Struggle and perspectives of the sexual minorities. Journal of Psychosexual Health, 2(2), 113-120. https://doi.org/10.1177/26318 31820939017

Banerjee, D., \& Rao, T. S. S. (2020). Sexuality, sexual well being, and intimacy during COVID-19 pandemic: An advocacy perspective. Indian Journal of Psychiatry, 62(4), 418-426. https://doi.org/10. 4103/psychiatry.IndianJPsychiatry_484_20 
Bosman, J., Mervosh, S., \& Santora, M. (2020). As the coronavirus surges, a new culprit emerges: Pandemic fatigue. The New York Times.

British Columbia Ministry of Health. (2020). COVID-19: Guidance for sex workers (Coronavirus COVID-19). Retrieved from http:// www.bccdc.ca/health-info/diseases-conditions/covid-19/preve ntion-risks/covid-19-and-sex.

Calabrese, S. K. (2020). Understanding, contextualizing, and addressing PrEP stigma to enhance PrEP implementation. Current HIV/AIDS Reports, 17(6), 579-588. https://doi.org/10.1007/ s11904-020-00533-y

Centers for Disease Control and Prevention. (2016). Gay and bisexual men's health: Suicide and violence prevention. Retrieved from https://www.cdc.gov/msmhealth/suicide-violence-prevention.htm.

Centers for Disease Control and Prevention. (2020). Sex and Covid-19: Frequently asked questions. Retrieved from https://npin.cdc.gov/ publication/sex-and-covid-19-frequently-asked-questions.

Fish, J. N., McInroy, L. B., Paceley, M. S., Williams, N. D., Henderson, S., Levine, D. S., \& Edsall, R. N. (2020). "I'm kinda stuck at home with unsupportive parents right now": LGBTQ youths' experiences with COVID-19 and the importance of online support. Journal of Adolescent Health, 67(3), 450-452.

Fuchs, A., Matonóg, A., Pilarska, J., Sieradzka, P., Szul, M., Czuba, B., \& Drosdzol-Cop, A. (2020). The impact of COVID-19 on female sexual health. International Journal of Environmental Research and Public Health, 17(19). https://doi.org/10.3390/ijerph1719 7152

Gibb, J., DuBois, L., Williams, S., McKerracher, L., Juster, R.-P., \& Fields, J. (2020). Sexual and gender minority health vulnerabilities during the COVID-19 health crisis [Commentary]. American Journal of Human Biology. https://doi.org/10.1002/ajhb.23499

Griffin, M., Martino, R. J., LoSchiavo, C., Comer-Carruthers, C., Krause, K. D., Stults, C. B., \& Halkitis, P. N. (2021). Ensuring survey research data integrity in the era of internet bots. Quality \& Quantity. https://doi.org/10.1007/s11135-021-01252-1

Grov, C., Zohra, F., Westmoreland, D. A., Mirzayi, C., D’Angelo, A., Stief, M., Kulkarni, S., Nash, D., \& Carrico, A. W. (2021). Sex in the era of COVID-19 in a U.S. national cohort of cisgender men, transgender women, and transgender men who have sex with men: April-May 2020. Archives of Sexual Behavior. https://doi.org/10. 1007/s10508-021-02121-6

Grubbs, J. B., Perry, S., Kraus, S. W., \& Grant, J. T. (2021). Porndemic? A longitudinal study of pornography use before and during the COVID-19 pandemic in a nationally representative sample of Americans. Archives of Sexual Behavior. https://doi. org/10.1007/s10508-021-02077-7

Human Rights Campaign. (2021). \#Outlawed: "The love that dare not speak its name”. Retrieved from https://features.hrw.org/featu res/features/lgbt_laws/single.html.

Kneale, D., \& Becares, L. (2020). The mental health and experiences of discrimination of LGBTQ+ people during the COVID-19 pandemic: Initial findings from the Queerantine Study. MedRxiv.

Krause, K. D. (2021). Implications of the COVID-19 pandemic on LGBTQ communities. Journal of Public Health Management and Practice, 27, S69-S71.

Lehmiller, J. J., Garcia, J. R., Gesselman, A. N., \& Mark, K. P. (2021). Less sex, but more sexual diversity: Changes in sexual behavior during the COVID-19 coronavirus pandemic. Leisure Sciences, 43, 295-304. https://doi.org/10.1080/01490400.2020.1774016

Lenke, K., \& Piehl, M. (2009). Women who have sex with women in the global HIV pandemic. Development, 52(1), 91-94.

Li, G., Tang, D., Song, B., Wang, C., Qunshan, S., Chuan, X., Geng, H., Huan, W., He, X., \& Cao, Y. (2020). Impact of the COVID-19 pandemic on partner relationships and sexual and reproductive health: Cross-sectional, online survey study. Journal of Medical Internet Research, 22(8), e20961. https://doi.org/10.2196/20961
Lindberg, L. D., Bell, D. L., \& Kantor, L. M. (2020). The sexual and reproductive health of adolescents and young adults during the COVID-19 pandemic. Perspectives on Sexual and Reproductive Health, 52(2), 75-79. https://doi.org/10.1363/psrh.12151

Lopes, G. P., Vale, F. B. C., Vieira, I., da Silva Filho, A. L., Abuhid, C., \& Geber, S. (2020). COVID-19 and sexuality: Reinventing intimacy [Letter to the Editor]. Archives of Sexual Behavior, 49(8), 2735-2738. https://doi.org/10.1007/s10508-020-01796-7

Mccrone, S. (2018). LGBT healthcare disparities, discrimination, and societal stigma: The mental and physical health risks related to sexual and/or gender minority status. American Journal of Medical Research, 5(1), 91-96.

McKay, T., Henne, J., Gonzales, G., Quarles, R., Gavulic, K. A., \& Gallegos, S. G. (2020). The COVID-19 pandemic and sexual behavior among gay and bisexual men in the United States. SSRN Electronic Journal. https://doi.org/10.2139/ssrn.3614113

New York City Department of Health and Mental Hygiene. (2020). Safer sex and COVID-19. Retrieved from https://www1.nyc.gov/ assets/doh/downloads/pdf/imm/covid-sex-guidance.pdf.

Newman, P. A., \& Guta, A. (2020). How to have sex in an epidemic redux: Reinforcing HIV prevention in the COVID-19 pandemic. AIDS and Behavior, 24, 2260-2264.

Orientations and Surveys. (2016). Current measures of sexual orientation and gender identity in federal surveys. In: Federal Committee on Statistical Methodology Washington, DC.

Pérez-Figueroa, R. E., Lurry, M., Thompson, M., Obonyo, D. J., Santella, A. J., \& Hyden, C. (2021). Raising awareness about COVID-19 among sexual minority men of color: Sex and the coronavirus, 2020. Annals of LGBTQ Public and Population Health, 1(4), 269-276.

Phillips, G., II., Felt, D., Ruprecht, M. M., Wang, X., Xu, J., PérezBill, E., Bagnarol, R. M., Roth, J., Curry, C. W., \& Beach, L. B. (2020). Addressing the disproportionate impacts of the COVID19 pandemic on sexual and gender minority populations in the United States: Actions toward equity. LGBT Health, 7(6), 279282. https://doi.org/10.1089/lgbt.2020.0187

Power, K. (2020). The COVID-19 pandemic has increased the care burden of women and families. Sustainability: Science, Practice and Policy, 16(1), 67-73. https://doi.org/10.1080/15487733. 2020.1776561

Salerno, J. P., Williams, N. D., \& Gattamorta, K. A. (2020). LGBTQ populations: Psychologically vulnerable communities in the COVID-19 pandemic. Psychological Trauma: Theory, Research, Practice, and Policy, 12(S1), S239-S242. https://doi.org/10.1037/ tra0000837

Sanchez, T. H., Zlotorzynska, M., Rai, M., \& Baral, S. D. (2020). Characterizing the impact of COVID-19 on men who have sex with men across the United States in April, 2020. AIDS and Behavior, 24, 2024-2032.

Scroggs, B., Love, H. A., \& Torgerson, C. (2020). COVID-19 and LGBTQ emerging adults: Risk in the face of social distancing. Emerging Adulthood. https://doi.org/10.1177/2167696820968699

Sevilla, A., \& Smith, S. (2020). Baby steps: The gender division of childcare during the COVID-19 pandemic. Oxford Review of Economic Policy, 36, S169-S186. https://doi.org/10.1093/oxrep/ graa027

Singer, R., Crooks, N., Johnson, A. K., Lutnick, A., \& Matthews, A. (2020). COVID-19 prevention and protecting sex workers: A call to action [Letter to the Editor]. Archives of Sexual Behavior, 49(8), 2739-2741. https://doi.org/10.1007/s10508-020-01849-x

Starks, T. J., Jones, S. S., Sauermilch, D., Benedict, M., Adebayo, T., Cain, D., \& Simpson, K. N. (2020). Evaluating the impact of COVID-19: A cohort comparison study of drug use and risky sexual behavior among sexual minority men in the USA. Drug and Alcohol Dependence, 216. https://doi.org/10.1016/j.drugalcdep. 2020.108260 
Stephenson, R., Chavanduka, T. M. D., Rosso, M. T., Sullivan, S. P., Pitter, R. A., Hunter, A. S., \& Rogers, E. (2020). Contrasting the perceived severity of COVID-19 and HIV infection in an online survey of gay, bisexual, and other men who have sex with men during the USA COVID-19 epidemic. American Journal of Men's Health, 14(5). https://doi.org/10.1177/1557988320957545

Su, D., Irwin, J. A., Fisher, C., Ramos, A., Kelley, M., Mendoza, D. A. R., \& Coleman, J. D. (2016). Mental health disparities within the LGBT population: A comparison between transgender and nontransgender individuals. Transgender Health, 1(1), 12-20. https:// doi.org/10.1089/trgh.2015.0001

Torres, T. S., Hoagland, B., Bezerra, D. R., Garner, A., Jalil, E. M., Coelho, L. E., Benedetti, M., Pimenta, C., Grinsztejn, B., \& Veloso, V. G. (2021). Impact of COVID-19 pandemic on sexual minority populations in Brazil: An analysis of social/racial disparities in maintaining social distancing and a description of sexual behavior. AIDS and Behavior, 25, 73-84.

Turban, J. L., Keuroghlian, A. S., \& Mayer, K. H. (2020). Sexual health in the SARS-CoV-2 era. Annals of Internal Medicine, 173, 387-389.

Wallman, K. K., Evinger, S., \& Schechter, S. (2000). Measuring our nation's diversity: Developing a common language for data on race/ethnicity. American Journal of Public Health, 90(11), 1704.

World Health Organization. (2010). Developing sexual health programmes: A framework for action. Retrieved from https://apps.
who.int/iris/bitstream/handle/10665/70501/WHO_RHR_HRP_10. 22_eng.pdf;jsessionid=1877EF764A598D0B9D8A34CEFF41E7 $\mathrm{CE}$ ? sequence $=1$.

Yong, E. (2020). How the pandemic defeated America: A virus has brought the world's most powerful country to its knees. The Atlantic. Retrieved from https://www.theatlantic.com/magazine/archive/ 2020/09/coronavirus-american-failure/614191/.

Zattoni, F., Gül, M., Soligo, M., Morlacco, A., Motterle, G., Collavino, J., Barneschi, A. C., Moschini, M., \& Dal Moro, F. (2020). The impact of COVID-19 pandemic on pornography habits: A global analysis of Google trends. International Journal of Impotence Research, 33(8), 824-831. https://doi.org/10.1038/ s41443-020-00380-w

Zhao, J., Lee, M., Ghader, S., Younes, H., Darzi, A., Xiong, C., \& Zhang, L. (2020). Quarantine fatigue: First-ever decrease in social distancing measures after the COVID-19 pandemic outbreak before reopening United States. arXiv preprint http://arxiv. org/abs/2006.03716.

Publisher's Note Springer Nature remains neutral with regard to jurisdictional claims in published maps and institutional affiliations. 